\title{
Do electoral rules have an effect on electoral behaviour? An impact assessment
}

\section{Ruth Dassonneville, Marc Hooghe \& Michael S. Lewis-Beck}

To cite this article: Ruth Dassonneville, Marc Hooghe \& Michael S. Lewis-Beck (2017) Do electoral rules have an effect on electoral behaviour? An impact assessment, West European Politics, 40:3, 503-515, DOI: 10.1080/01402382.2016.1271597

To link to this article: http://dx.doi.org/10.1080/01402382.2016.1271597

册Published online: 24 Jan 2017.

Submit your article to this journal $\widetilde{\sigma}$

III Article views: 361

Q View related articles $\asymp$

View Crossmark data $₫$

4 Citing articles: 2 View citing articles 진 


\title{
Do electoral rules have an effect on electoral behaviour? An impact assessment
}

\author{
Ruth Dassonneville ${ }^{a}$, Marc Hooghe ${ }^{b}$ and Michael S. Lewis-Beck ${ }^{c}$ \\ aDépartement de science politique, Université de Montréal, Montréal QC Canada; ${ }^{b}$ Centre for \\ Citizenship and Democracy, University of Leuven, Leuven, Belgium; 'Department of Political \\ Science, University of lowa, lowa City, USA
}

\begin{abstract}
Electoral democracies worldwide are all organised around elections but the rules under which the elections are organised differ greatly from one country to another. These electoral rules, such as whether voting is compulsory or what electoral system is used, are thought of as strongly affecting voters' behaviour and the choices they make. If electoral rules indeed shape citizens' electoral behaviour, the implication is that theories of what explains voters' choices are country-specific as well. This is in sharp contrast to the idea that theories of electoral behaviour are generalisable. This special issue tackles this question and offers an assessment of the impact of electoral rules on voters' behaviour, on the one hand, and the generalisability of individual-level theories of voting behaviour, on the other. The collection of papers furthermore offers an important contribution in terms of the kind of electoral rules that are scrutinised, with several papers focusing on the little-investigated phenomenon of preferential voting.
\end{abstract}

KEYWORDS Electoral rules; electoral behaviour; electoral system; comparative research

Scholars of electoral behaviour commonly assume voting to be strongly affected by the institutional context in which citizens are embedded. Electoral rules, and efforts to change them, are highly salient topics in the public and political debate as well, because of the assumption that voters' behaviour is affected by these rules and because of expectations that citizens would behave differently if the rules were changed. The general expectation, therefore, seems to be that electoral rules matter, because they will have an effect on voters, and therefore also on electoral outcomes. With the term 'electoral rules' we refer here to the rules under which elections are organised, such as whether voting is compulsory, or whether a majoritarian or proportional electoral system operates. In general, electoral rules are expected to influence whether and how citizens cast a vote. Moreover, we observe a very strong variation with regard to the 
electoral systems functioning in various countries. Further, these systems tend to be rather resistant to any effort to change them (Farrell 2011). With a few exceptions, like Italy or New Zealand, electoral rules mostly can be regarded as stable country characteristics (Gallagher 1998). Therefore it makes sense to assume that these marked differences could have an impact on the way voters interact with the political system, most notably in the context of elections.

More than half a century ago Maurice Duverger (1951) claimed that electoral systems fundamentally shape voting behaviour and its determinants. Since then, numerous scholars have investigated and reported on the effect of electoral rules on voters (Blais and Carty 1991). First, comparative work that describes electoral behaviour across a number of countries, where electoral rules vary in a significant manner, has given indications of fundamental differences. Research on electoral participation, for example, consistently finds higher turnout levels in countries with a proportional electoral system as compared to majoritarian electoral systems (Geys 2006). Compulsory voting rules, too, clearly have a positive effect on turnout levels, suggesting that these rules matter in the individual decision to vote (Birch 2013). Second, causality claims have been strengthened by experimental work on the impact of electoral systems. Van der Straeten and her colleagues (2010), for example, have run a series of laboratory experiments which conclude that the extent to which citizens vote strategically depends on electoral rules. Third, the low external validity of such lab experiments has been addressed by means of quasi- and naturalexperimental studies. These studies also give indications of a non-negligible impact of electoral rules, on electoral participation as well as on voters' choices (Fowler 2013; Karp and Banducci 1999). A recent study by Sanz (forthcoming) is exemplary in this regard. This paper exploits the natural variation in the electoral rules of local elections in Spain, showing that turnout increases when local representatives are elected on open lists, as compared to closed-list elections. From this brief overview of previous work and different research strategies, it becomes evident that electoral rules seem to matter (Norris 2004). The decision to turn out to vote, not to mention what candidates or parties a voter chooses, are influenced by the rules of the game. Following Duverger, electoral systems apparently have strong and significant psychological effects.

This line of reasoning has indeed a solid theoretical basis. The presence of institutions, one assumes, shapes human behaviour and upholds this behaviour, since these norms are ultimately interiorised by the citizens. This kind of loyalty leads to social stability, as Parsons (1951) famously assumed in his classical theory. Electoral rules can be considered as part of the institutional framework of a society because they determine the allocation of power and because their stability plays a constitutive role in politics (Bowler and Donovan 2003). The agency of individual voters and citizens, therefore, should be bound by these electoral rules. This implies that norms of rational behaviour by citizens can also vary, depending, for example, on whether the institutions they live in are based on a majoritarian or a representative logic. 
While electoral systems are generally found to matter for the vote choice, a more fundamental theoretical implication of Duverger's work tends to be unappreciated. That is, the claim that electoral systems have a systematic and strong impact on voters calls into question the generalisability of vote choice models, across countries and electoral systems. Scholars examining the determinants of the vote choice have devoted quite some attention and effort to detecting general patterns. Theories, survey methods, as well as question wording for crucial concepts have travelled from one country to another. Originally, similarities in the question wording of survey items of national election surveys in different countries were the result of rather ad hoc efforts by "missionaries" from Michigan', the birthplace of the highly influential American National Election Studies (Knight and Marsh 2002: 173). Recently, more systematic efforts at harmonisation have been undertaken - for example, the True European Voter project has set out to harmonise the data from existing election studies across Europe, so allowing the testing of fundamental theories of voting behaviour. In addition, the Comparative Study of Electoral Systems (CSES) project offers a leading example of coordination in data gathering, as it revolves around the administration of identical questions in election studies from over 50 democracies worldwide. These large data efforts are in part inspired by the notion that comparative analyses will allow us to shed more light on the general characteristics of the vote choice process.

Such efforts permit a more systematic assessment of the generalisability of some fundamental theories. These theories of the voting behaviour originate mostly, though not exclusively, from scholars investigating electoral behaviour in the United States. Take, for example, the focus on partisanship as a key variable for explaining voters' behaviour and choices. While the concept of partisanship emanates from the ground-breaking work of Campbell and his colleagues (1960), many other scholars have sought to measure and verify its impact on the vote choice in countries worldwide, assuming that the concept of partisanship could be present in other political systems as well (Bartle and Bellucci 2014; Lupu 2015). Similarly, theories of economic voting have travelled from the United States, where they were originally proposed and tested, to a large and varied set of electoral contexts (Lewis-Beck and Stegmaier 2000). Many more examples could be referred to, such as work on strategic voting which has been examined in majoritarian as well as in proportional electoral systems (Gschwend 2007) - or work on the impact of party leaders on the vote choice (Aarts et al. 2013). These studies share a fairly obvious conviction that some fundamental theories of voting behaviour are generalisable across a large and varied set of contexts. Finding that patterns are generalisable can be important from a normative point of view as well. Citizens using their vote to hold incumbents and politicians accountable for their performance stands as a key aspect of elections, one allowing for the realisation of representative democracy (Przeworski et al. 1999). Holding politicians accountable is, indeed, 
an essential component of democracy. As such, finding economic voting in a large and varied set of democracies bears witness to their well-functioning, representative nature.

The essential challenge of Duverger's work, however, lies in the impact of institutional and systemic differences between countries. If he is right, and electoral systems fundamentally shape voters' behaviour and the choices they make, differences in electoral rules severely limit the potential to generalise research results on the individual-level factors that explain the vote. The impact of electoral rules could be such that the effect of individual-level determinants on the vote depends on specific characteristics of the electoral system. To express it differently, maybe in some countries one specific set of vote choice determinants is important, while in other countries, with different electoral rules, a totally different set of determinants might affect citizens' vote choices. That could mean that the search for generally applicable vote choice models is in vain, because the vote choice process is highly context-specific. In that case, the obvious conclusion should be that it is impossible to determine universal vote choice determinants, since voters tend to respond to a specific set of electoral rules. In summary, the effect of the electoral system on the vote choice process can be seen as a major challenge for electoral research and the generalisability of theories of voting behaviour, a challenge not often seriously addressed. The goal of this special issue is to offer such an assessment by investigating in a systematic and comparative manner what impact electoral rules have on specific vote choice processes and determinants.

\section{The micro- and the macro-level, direct and indirect effects}

When assessing the impact of electoral rules on the vote choice process, it is important to distinguish between different levels of analysis. Electoral rules are macro-variables specific to a particular context and usually highly stable - as is evident from some recent failed attempts to reform the electoral system in Britain and several Canadian provinces (Fournier et al. 2011; Whiteley et al. 2013). The vote, in contrast, is a micro-level variable, as it is individual citizens who decide whether to turn out to vote and whom to vote for in the polling booth. Any analysis of the impact of electoral rules has to be attentive to this difference in levels, because the problem of ecological fallacy implies that we cannot straightforwardly make inferences about individuals' behaviour from an aggregate-level analysis.

The literature on electoral rules does include a large number of studies that focus exclusively on the macro-level. Work in this tradition has offered important insights and a number of aggregate-level findings on the consequences of electoral rules prove to be quite robust. To mention only one example, levels of turnout are consistently found to be higher under proportional representation 
(PR) rules. Aggregate-level studies have a number of important advantages, such as the fact that they rely on precise estimates of the vote share or turnout, and not on respondents' reported behaviour, which is more error-prone. Aggregate-level studies, however, do not allow strong conclusions to be drawn about individuals' political behaviour. Substantial variation in citizens' characteristics and attitudes can simply not be accounted for by an analysis of aggregate turnout patterns. Observed differences between countries that are ascribed to different electoral rules might therefore well be spurious.

It is such concerns that have motivated scholars to develop datasets that would allow the impact of electoral systems to be examined by means of individual-level analyses. The data from the CSES project, for example, consist of individual-level measures of citizens' behaviour as well as their attitudes in a large set of democracies. By means of these data, or by pooling other survey data from different countries, research designs can be developed that allow the consequences of differences in electoral rules at the individual level to be assessed.

Assessing the impact of electoral rules at the individual level is also theoretically important, because aggregate-level differences should be grounded in individual-level mechanisms. While some macro-level findings on electoral rules are strong and robust, our understanding of the individual-level mechanisms explaining these macro-observations is still limited (Blais and Aarts 2006). A number of scholars have used the available comparative individual-level survey data to investigate such questions, and to examine the impact of contextual factors by means of individual-level data. Surprisingly, however, these studies do not always corroborate the strong macro-level evidence. The detailed analysis by Brockington (2004) of individual-level sources of turnout on CSES data, for example, did not allow him to unveil what individual-level mechanisms explain why turnout is higher under PR rules. This only adds to the theoretical puzzle: empirically we know there are strong differences between countries. If, however, there is no direct impact of country-level variables on the behaviour of citizens, it remains a challenge to explain the occurrence of these differences, since other causal mechanisms must be at play. Electoral rules might, for example, have an effect because they affect political actors' behaviour. Hooghe et al. (2006), for example, suggest that the effects of electoral reform (specifically the introduction of an electoral threshold in Belgium) cannot be explained by the effect it had on individual voters, but solely by the effect it had on the strategic and anticipatory behaviour of political parties. While on an aggregate level one might draw the conclusion that changing the rules would have had an effect on voters' behaviour, this clearly was not the case.

As an additional advantage, individual-level comparative research allows for looking beyond the direct effects of electoral rules on citizens' political behaviour. Individual-level theories of the vote choice usually depart from quite general models and assume that some traditional vote choice determinants, 
such as partisanship or the economy, affect voters' decisions in the same way across democracies. By combining individual-level data from different countries and settings, one can relax this assumption, and verify whether citizens' vote choice calculus is effectively the same regardless of the electoral rules. Doing so, we gain insights into the indirect effects of electoral systems, as well as in how electoral rules moderate individual-level mechanisms. Previous work along these lines that examined the indirect and moderating impact of electoral rules, however, has not given indications of a strong impact of electoral rules. This observation has led Thomassen (2014b: 19) to conclude that 'Political institutions are less relevant for people's attitudes and behaviour than often presumed'. If this observation is correct, it would imply that (changing) electoral systems should not have a major impact on the way voters make up their mind. If, however, electoral rules do not fundamentally alter the vote choice calculus of citizens, then scholarly efforts to generalise and apply similar vote choice models in varying electoral contexts appears a sound and sensible research strategy.

The rather weak and sometimes even conflicting results from previous work (Thomassen 2014a) that has combined aggregate- and individual-level approaches clarify that macro- and the micro-approaches toward the explanation of electoral behaviour are in need of further dialogue. One goal of this special issue is to contribute to this ongoing debate by offering new empirical evidence on the impact of electoral rules and institutions on determinants of individual-level voter behaviour.

The articles that are included in this special issue rely on different datasets and the methodological approaches that are used are also varied. A number of papers are focused on the macro-level, while other articles in this collection examine the impact of electoral rules by means of individual-level datasets. The individual-level analyses differ as well, with some papers focusing on the direct effects of electoral rules on individuals' behaviour and other papers aiming to disentangle the indirect and moderating effects of electoral rules. Bringing together research that examines the effects of electoral rules from different angles and with different types of datasets makes for a collection of papers that reflects well the state of the art in this field. In addition, since each approach has advantages and disadvantages, a combination of methods offers the most comprehensive view of how electoral rules matter for the vote choice.

The papers in this special issue are innovative in a number of ways. Several papers focus on aspects of electoral systems that have so far received little attention in the literature. Most importantly, three of the articles included take into account different ways in which electoral systems allow voting for candidates and how that affects citizens' behaviour. In this way, the papers are taking new steps that will undoubtedly inspire more research on the topic. 


\section{Structure and contributions of this special issue}

The first paper by Peter Söderlund (2017) is a macro-level study of the impact of candidate-centred electoral systems on turnout. By means of a thorough analysis of data from 36 democracies since 1990, the author examines whether electoral systems that focus more on candidates increase or on the contrary depress turnout. The results show that turnout is lower in candidate-centred systems. This finding holds regardless of what indicator of candidate-centredness is used and it appears to be robust for a large number of control variables, such as the number of parties in a system, or how disproportional an electoral system is. Söderlund's analysis thus offers strong evidence of a systemic effect of electoral rules on electoral participation; aggregate levels of participation are lower when candidate-based ballots are used. Söderlund also offers a suggestion for an individual-level mechanism that could explain this aggregate-level pattern: candidate-centred systems broaden the number of options a voter can choose from, rendering voting more cognitively challenging. The aggregate-level data used in the article do not allow this individual-level mechanism to be put to the test, but Söderlund's strong macro-level findings clearly can set the agenda. While it is often assumed that a focus on candidates might make voting more appealing for voters, this can also lead to a cognitive overload, leading to abstention by potential voters. The article calls for more research to disentangle the consequences of the extent to which electoral systems are candidate-centred.

The second paper by Ruth Dassonneville and Michael Lewis-Beck (2017) offers an aggregate-level analysis as well, but the focus is shifted from turnout to voters' choices. This paper relies on a database of 474 elections in 34 countries to examine cross-national variation in economic voting. In the analysis, the impact of changes in GDP growth on the incumbent vote share is analysed. Previous research has argued that the extent to which incumbents are held accountable for the state of the economy depends on institutional rules and the distribution of power. That is, studies have found the economy to affect the incumbent's vote share in high-clarity contexts only, but not in contexts where it is less clear who is responsible for government decisions. Dassonneville and LewisBeck, however, test this expectation interactively and they find that economic voting is not significantly weaker in low-clarity contexts than in high-clarity contexts. This holds regardless of whether they look at institutional rules such as the electoral system or whether they consider patterns of power sharing. From these essentially null results, Dassonneville and Lewis-Beck conclude that economic voting is a more general pattern than regularly assumed. The impact of electoral rules on economic voting, while not absent, is hence more limited than is generally assumed, implying that economic voting can be considered as a rather general pattern within electoral democracies.

Liisa Talving's (2017) article also examines economic voting cross-nationally, though her efforts differ in two important respects from the previous paper. 
First, she examines economic voting by means of individual-level data, obtained from the European Election Studies (EES) project. Second, Talving does not focus on reward and punishment for economic growth, but examines voters' reaction to the economic policies that governments implement. Talving pools data from 24 European countries and three EES studies (2004, 2009 and 2014), which allows her to compare voting behaviour before and after the outbreak of the economic and financial crisis starting in 2008. Talving finds that governments that pursued austerity measures were punished by voters, but only in the aftermath of the economic crisis. This indication of economic policy voting, furthermore, is found to be fairly general, as Talving finds no indications of this effect being conditional on the extent to which national governments are tied by supranational or international institutions. In line with Dassonneville and Lewis-Beck's results on economic performance voting, thus, Talving's findings show effects that are quite general, regardless of important cross-national differences in her sample.

Pedro Riera and Damien Bol's contribution (2017) examines patterns of splitticket voting in two types of mixed-member electoral systems: mixed-member proportional systems (MMP) on the one hand and mixed-member majoritarian (MMM) systems on the other. Riera and Bol argue that these different systems offer different incentives for split-ticket voting. More specifically, they theorise that under MMP rules, voters have more incentives to desert their preferred party for the candidate vote than under MMM systems, because the vote they cast for a candidate of another party does not affect the proportion of seats in parliament their preferred party will obtain. Riera and Bol make use of election survey data from seven different electoral contexts and offer indications that split-ticket voting is indeed higher under MMP rules, and this finding is robust to controlling for a series of relevant correlates of split-ticket voting. Even though the data that Riera and Bol muster are somewhat limited and cover a select number of countries, their results are in line with expectations. In showing important effects on voting behaviour of what seems like a minor element of electoral system engineering, they make a strong argument that scholars of electoral systems and voting behaviour should pay attention to the full complexity of electoral rules - and not rely on a crude categorisation of electoral systems only when examining the impact of electoral rules.

The next contribution in this special issue is by Audrey André and Sam Depauw (2017), who examine the determinants of casting preference votes for candidates. The paper focuses on electoral systems where voters can either vote for a party list or support specific candidates and sets out to examine the impact of institutional rules on the probability of casting preference votes. André and Depauw use data from the CSES project and complement this with survey data from Belgium, which allows them to analyse preference voting in six countries (Austria, Belgium, Czech Republic, Latvia, Sweden and Switzerland). They present a district-level analysis as well as analyses using individual-level 
data, which allow them to examine whether some voters are more affected by institutional rules than others. The findings of André and Depauw suggest that institutional rules matter; voters are more likely to cast preference votes when they have a limited number of candidates to choose from and when these preference votes effectively influence who gets a seat in parliament. The results of this paper furthermore show that institutional rules matter more for highly politically sophisticated voters, suggesting that they are significant only for those voters who understand the rules of the game.

A final paper in this collection examines the effects of compulsory voting rules on the quality of the vote choice. Using data from the CSES project, Ruth Dassonneville, Marc Hooghe and Peter Miller (2017) analyse the determinants of the vote choice in over 100 elections worldwide. They focus on two vote choice determinants that are deemed important in the normative literature on representative democracy; accountability and proximity. For examining accountability mechanisms, they focus on economic voting and assess the impact of GDP growth as well as unemployment rates on voting for an incumbent party. Proximity voting is operationalised in a traditional way and relates to ideological proximity in terms of left and right. The results that are presented in this paper show an interesting contrast between accountability on the one hand and proximity voting on the other. Compulsory voting rules do not seem to affect the extent to which incumbents are held accountable for the state of the economy. These results add further evidence to the observations of Dassonneville and Lewis-Beck as well as those of Talving. Economic considerations affect voters' choices in a fairly general way, and institutions or electoral rules do not appear to hamper such behaviour. In terms of proximity voting, in contrast, Dassonneville et al. find that voters are less likely to vote for the most proximate party when voting is mandatory.

\section{Conclusion: what effect do electoral rules have on electoral behaviour?}

The overall conclusion from these articles suggests that the general claim about the psychological effects of electoral rules needs to be qualified. To some extent voters are influenced by electoral rules, and they adapt their behaviour accordingly. Especially with regard to the question on what ground voters decide to vote for a list or for one or more specific candidates, we have observed significant differences across political systems. This finding does pose a challenge for efforts to arrive at generalisable models for explaining voting behaviour: as the vote choice process of citizens seems be heavily influenced by specifics of the electoral system, one cautious suggestion for future research should be that these between-country variations should play a role in comparative research. Importantly, we find distinctions in the extent to which citizens are influenced by electoral rules. Political sophistication seems to play a key role here, since 
the most sophisticated voters apparently understand the rules better, or are better able to adapt their behaviour to fit with the electoral rules. Insight into the working of the electoral rules, therefore, might be an element permitting sophisticated voters to express their vote more effectively. If voters do not fully understand the consequences of electoral rules, this limits their ability to use those rules to get their voice heard in the policy process. This, too, is a sobering conclusion. Within the field of political science, various proposals have been put on the table, in order to arrive at electoral reform. Whatever the scientific merits of these proposals, increasing the complexity of an electoral system comes at a price, as it allows the more sophisticated to use their vote more strategically, while lessening the transparency of the political process, especially for voters with lower levels of political sophistication.

Some other vote choice determinants, like economic voting, on the other hand, seem to be so prevalent that they are apparently immune to this kind of country-level influence. They appear quite general, making it worthwhile to investigate further what kind of voting motives can, indeed, be seen as 'universal'. For future research, the question does remain open whether electoral accountability, as operationalised by economic voting, really is as robust to the effect of electoral rules as it appears to be based on these results. Moreover, this finding has an importance from a normative point of view. It has been argued repeatedly that realising representation and accountability are the two main functions of elections. If that is the case, both functions should be robust against a wide array of forms of electoral engineering. Electoral engineering, as it has been called, should therefore be tailored to meet the most fundamental functions of democracy: representation and accountability.

Based on the results of the articles included in this special issue, our conclusions might appear to be a bit middle of the road. Obviously, electoral rules do have an impact on some element of the vote decision process. With regard to candidate voting, or the decision to turn out or not, we do see important differences across countries. Apparently, there is a sufficient level of agency among citizens to ensure that they react to the possibilities and limits that are offered by the electoral system. It is important, however, to refer back to the two main functions of elections in a democratic political system: representation and accountability. As we have seen, representation can be influenced by changing electoral rules. Abolishing compulsory voting, for example, almost automatically ensures that the electorate will be less representative for the voting age population as a whole. Complex systems of voter registration can further erode the representative function of elections. On the other hand, for the main voting motives that help to enable the accountability function of electoral democracy, there seems to be sufficient evidence that they are remarkably robust. No matter what the electoral rules might be, incumbents do seem to be held accountable for the way they have managed the national economy. This 
accountability mechanism, which is at the heart of electoral democracy, seems to a large extent to be remarkably resistant to country-level differences, and both from a normative point of view, as from the perspective of comparative political science, this is rather good news.

\section{Acknowledgements}

Most of the articles in this special issue were first presented at the conference 'Comparative Perspectives on Electoral Behaviour: The Impact of the Electoral and Party System', held at the Academia Belgica in Rome, on 16-18 September 2015. We thank the Academia for the hospitality, Ms Greet Louw for organising the event, and the participants for comments and suggestions on the papers. The guest editors also want to thank all the reviewers for their critical comments that have greatly improved the papers.

\section{Disclosure statement}

No potential conflict of interest was reported by the authors.

\section{Funding}

This work was supported by Canada Research Chairs [grant number 950-231173]; Fonds de Recherche du Québec-Société et Culture [grant number 2017-NP-199028].

\section{Notes on contributors}

Ruth Dassonneville is an Assistant Professor in the Department of Political Science at Université de Montréal, where she holds the Canada Research Chair in Electoral Democracy. Her main research interests are dealignment, voting behaviour, economic voting and election forecasting. Her work has been published in, amongst others, Electoral Studies, European Journal of Political Research, Party Politics and Political Studies. [ruth.dassonneville@umontreal.ca]

Marc Hooghe is a Professor of Political Science at the University of Leuven (Belgium), where he holds an Advanced Grant of the European Research Council (ERC) to investigate the democratic linkage between citizens and the state in Europe. He is also director of the Centre for Citizenship and Democracy at the University of Leuven. He has published mainly on political participation, electoral behaviour, political trust and social capital. [marc.hooghe@kuleuven.be]

Michael S. Lewis-Beck is F. Wendell Miller Distinguished Professor of Political Science at the University of Iowa. His interests are comparative elections, election forecasting, political economy, and quantitative methodology. Professor Lewis-Beck has authored or co-authored over 250 articles and books, including Economics and Elections, The American Voter Revisited, French Presidential Elections, Forecasting Elections, The Austrian Voter and Applied Regression. He has served as Editor of the American Journal of Political Science and of the Sage QASS series (the green monographs) in quantitative methods. Currently he is Associate Editor of International Journal of Forecasting and of French Politics. [michael-lewis-beck@uiowa.edu] 


\section{References}

Aarts, Kees, André Blais, and Herman Schmitt, eds. (2013). Political Leaders and Democratic Elections. Oxford: Oxford University Press.

André, Audrey, and Sam Depauw (2017). 'Too Much Choice, Too Little Impact: A Multilevel Analysis of the Contextual Determinants of Preference Voting, West European Politics. http://dx.doi.org/10.1080/01402382.2016.1271596.

Bartle, John, and Paolo Bellucci (2014). Political Parties and Partisanship: Social Identity and Individual Attitudes. London: Routledge.

Birch, Sarah (2013). Full Participation: A Comparative Study of Compulsory Voting. Manchester, NH: Manchester University Press.

Blais, André, and Kees Aarts (2006). 'Electoral Systems and Turnout', Acta Politica, 41:2, 180-196.

Blais, André, and R. Kenneth Carty (1991). 'The Psychological Impact of Electoral Laws. Measuring Duverger's Elusive Factor', British Journal of Political Science, 21:1, 79-93.

Bowler, Shaun, and Todd Donovan, eds. (2003). The Limits of Electoral Reform. Oxford: Oxford University Press.

Brockington, David (2004). 'The Paradox of Proportional Representation: The Effect of Party Systems and Coalitions on Individuals' Electoral Participation', Political Studies, 52:3, 469-490.

Campbell, Agnus, Philip E. Converse, Warren E. Miller, and Donald E. Stokes (1960). The American Voter. New York, NY: John Wiley.

Dassonneville, Ruth, Marc Hooghe, and Peter Miller (2017). 'The Impact of Compulsory Voting on Inequality and the Quality of the Vote', West European Politics. http:// dx.doi.org/10.1080/01402382.2016.1266187.

Dassonneville, Ruth, and Michael Lewis-Beck (2017). 'Rules, Institutions and the Economic Vote: Clarifying Clarity of Responsibility', West European Politics. http:// dx.doi.org/10.1080/01402382.2016.1266186.

Duverger, Maurice (1951). Les partis politiques. Paris: A. Colin.

Farrell, David M. (2011). Electoral Systems: A Comparative Introduction. Basingstoke: Palgrave Macmillan.

Fournier, Patrick, Henk van der Kolk, R. Kenneth Carty, André Blais, and Jonathan Rose (2011). When Citizens Decide: Lessons from Citizen Assemblies on Electoral Reform. Oxford: Oxford University Press.

Fowler, Anthony (2013). 'Electoral and Policy Consequences of Voter Turnout: Evidence from Compulsory Voting in Australia, Quarterly Journal of Political Science, 8:2, 159-182.

Gallagher, Michael (1998). 'The Political Impact of Electoral System Change in Japan and New Zealand, 1996', Party Politics, 4:2, 203-228.

Geys, Benny (2006). 'Explaining Voter Turnout: A Review of Aggregate-Level Research', Electoral Studies, 25:4, 637-663.

Gschwend, Thomas (2007). 'Ticket-Splitting and Strategic Voting under Mixed Electoral Rules: Evidence from Germany', European Journal of Political Research, 46:1, 1-23.

Hooghe, Marc, Bart Maddens, and Jo Noppe (2006). 'Why Parties Adapt. Electoral Reform and Party Strategy in Belgium', Electoral Studies, 25:2, 351-368.

Karp, Jeffrey A., and Susan A. Banducci (1999). 'The Impact of Proportional Representation on Turnout: Evidence from New Zealand, Australian Journal of Political Science, 34:3, 363-377.

Knight, Kathleen, and Michael Marsh (2002). 'Varieties of Election Studies', Electoral Studies, 21:2, 169-187. 
Lewis-Beck, Michael S., and Mary Stegmaier (2000). 'Economic Determinants of Electoral Outcomes', Annual Review of Political Science, 3, 183-219.

Lupu, Noam (2015). 'Party Polarization and Mass Partisanship: A Comparative Perspective', Political Behavior, 37:2, 331-356.

Norris, Pippa (2004). Electoral Engineering. Voting Rules and Political Behaviour. Cambridge: Cambridge University Press.

Parsons, Talcott (1951). The Social System. Chicago, IL: Free Press.

Przeworski, Adam, Susan C. Stokes, and Bernard Manin (eds.) (1999). Democracy, Accountability, and Representation. Cambridge: Cambridge University Press.

Riera, Pedro, and Damien Bol (2017). 'Ticket-Splitting in Mixed-Member Systems: On the Importance of Seat Linkage between Electoral Tiers', West European Politics. http://dx.doi.org/10.1080/01402382.2016.1271598.

Sanz, Carlos (forthcoming). 'The Effect of Electoral Systems on Voter Turnout: Evidence from a Natural Experiment', Political Science Research and Methods.

Söderlund, Peter (2017). 'Candidate-Centred Electoral Systems and Voter Turnout', West European Politics. http://dx.doi.org/10.1080/01402382.2016.1271599.

Van der Straeten, Karine, Jean-François Laslier, Nicolas Sauger, and André Blais (2010). 'Strategic, Sincere, and Heuristic Voting under Four Election Rules: An Experimental Study', Social Choice and Welfare, 35:3, 435-472.

Talving, Liisa (2017). 'The Electoral Consequences of Austerity: Economic Policy Voting in Europe in Times of Crisis', West European Politics. http://dx.doi.org/10.1080/014 02382.2016.1271600.

Thomassen, Jacques, ed. (2014a). Elections and Democracy. Representation and Accountability. Oxford: Oxford University Press.

Thomassen, Jacques (2014b). 'Representation and Accountability', in Jacques Thomassen (ed.), Elections and Democracy. Representation and Accountability. Oxford: Oxford University Press, 1-19.

Whiteley, Paul, Harold D. Clarke, David Sanders, and Marianne C. Stewart (2013). Affluence, Austerity and Electoral Change in Britain. Cambridge: Cambridge University Press. 